\title{
AVALIAÇÃO DE POLÍTICAS DE PROGRAMAÇÃO NA FABRICAÇÃO DE COMPÓSITOS POR MEIO DE SIMULAÇÃO
}

\author{
W. R. Schmeal \\ EPRI Chemicals \& Petroleum \\ P. D. Parikh \\ Shell Development Co.
}

\begin{abstract}
[Tradução de Flávio Fernandes e publicação sob licença:
Reprinted from Industrial Engineering magazine, November 1993, Copyright 1993, Institute of Industrial Engineers, 25 Technology Park / Atlanta, Norcross, Georgia 30092.]
\end{abstract}

Foi feita uma avaliação da tecnologia de fabricação, por meio de simulação, para aplicações específicas de uma pequena fábrica de compósitos poliméricos. Os objetivos eram:

ý Avaliar o potencial de uso na otimização de operações existentes ou no planejamento de projetos futuros e de expansões;

ý Selecionar um software adequado;

ý Identificar recursos necessários; $e$

ý Recomendar um plano de implementação.

Deve-se salientar que o escopo da avaliação foi muito específico, visando as necessidades de uma pequena empresa, e que a procura foi limitada a pacotes de software existentes, de baixo custo e fáceis de usar.

A simulação foi aplicada a um novo projeto, fabricação e forração de invólucros para pneus e o avêsso de tecidos de assentos para dois modelos de automóvel. O processo 'Structural Reaction Injection Molding' (SRIM) foi usado para a fabricação, e o forro foi aplicado em uma seção de colagem e montagem. Esquemas de movimentação de materiais e capital tinham sido previamente determinados, deixando os modos de operação e as opções de programação das operações como as principais incógnitas do sistema. A simulação dos processos em operação forneceu uma perspectiva dos sistemas, levando a recomendações de estratégias de operações que não eram muito óbvias.

Palavras-chaves: simulação, programação de operações, fabricação de compósitos.

\section{Avaliação da Tecnologia}

A motivação para o uso da simulação como uma prática padronizada para plantas fabris pode ser tanto geral como específica.

A simulação pode ser um elo técnico crítico para a estratégia CIM (Computer Integrated Manufaturing). Ela pode aumentar o envolvimento e o entendimento amplo 
do modo pelo qual as várias seções da fábrica estão integradas. Especificamente, ela pode ser útil para:

ý identificação dos custos que podem ser evitados durante a especificação e o projeto do sistema;

ý avaliação inicial do programa projetado e do mix de modelos;

ý avaliação das estratégias operacionais durante o projeto do sistema; e

ý quantificação dos impactos das modificações propostas no sistema.

Após uma avaliação preliminar de seis principais produtos de simulação, selecionamos ProModelPC e WITNESS para uma avaliação adicional usando programas alugados para realizar um estudo de caso.

Os recursos necessários são hardware, software, treinamento de mão-de-obra, tempo de mão-de-obra e custos de consultoria externa. Os pacotes de software avaliados requerem um IBM AT ou um computador pessoal compatível, com 640K RAM, pelo menos uma placa gráfica e monitor EGA. O acesso a uma impressora laser é também desejável. Um modem é útil para a transmissão de programas para um staff técnico de suporte no local do fornecedor. O custo principal é o do treinamento da mão-de-obra.

\section{Estudo de Caso}

Um estudo foi realizado para avaliar várias abordagens de operação para moldagem e acabamento de invólucros para pneus. O estudo foi modelado com sucesso, e com resultados similares tanto para o ProModelPC quanto para o WITNESS.

Este estudo focalizou o layout e a operação de três prensas disponíveis e de uma prensa de corte para acabamento (retirada de rebarba) que tinha acabado de ser adquirida. A prensa de acabamento foi testada em uma área separada da instalação, e o assunto do estudo foi onde localiza-la, que esquema de movimentação de materiais usar e como os operadores deveriam ser atribuídos. Cada prensa era capaz de produzir um par de invólucros de pneus a cada dois minutos, e a prensa de acabamento tinha um tempo de ciclo de 24 segundos. Quatro, três e dois operadores foram atribuídos em vários cenários, e várias táticas de operação foram consideradas. Foi estudada a localização da prensa de acabamento, em relação às prensas de moldagem, como também a necessidade de uma correia transportadora e de uma segunda prensa de acabamento.

Operadores carregam a prensa com duas pré-fôrmas de fibra de vidro, iniciam a injeção de resina e descarregam a peça. Há uma injeção de resina e uma fase de cura da moldagem em que o operador não é necessário e pode realizar outra tarefa, tal como operar uma outra prensa, mover peças para a área de acabamento ou operar a prensa de acabamento. O sistema de injeção de resina permite a resina fluir apenas para uma prensa por vez.

Nove cenários foram considerados, envolvendo de dois a quatro operadores, várias localizações da prensa de acabamento, transporte manual de peças ou o uso de 
uma correia transportadora, e se operadores específicos devem dar prioridade à moldagem ou ao acabamento.

A taxa de produção para os casos de três ou quatro operadores foi de 1095 peças por turno de 7,5 horas, correspondendo à uma operação contínua da prensa de acabamento. Dois operadores foram capazes de produzir cerca de 840 peças por turno quando um operava duas prensas e o outro operava a prensa restante e a prensa de acabamento. Neste caso, um método de transporte - uma simples correia transportadora - é necessário para transportar peças das duas primeiras prensas para a prensa de acabamento, que é localizada perto da terceira prensa.

Casos de dois operadores podem ser mais eficientes em termos de produção por operador ou custo de mão-de-obra por peça. A produção por turno e a utilização de cada operador são mostradas na Tabela 1, para vários casos.

Tabela 1 - Resultados da Simulação para o Invólucro de Pneu

\begin{tabular}{|c|c|c|c|c|c|c|c|c|}
\hline & & $\begin{array}{l}\text { Utiliz } \\
\text { opera }\end{array}$ & $\begin{array}{l}\text { ão dos } \\
\text { res }\end{array}$ & Uso d & equip & nentos & & $\begin{array}{l}\text { Produ } \\
\text { ção }\end{array}$ \\
\hline $\begin{array}{l}\text { Descrição do } \\
\text { caso }\end{array}$ & $\begin{array}{l}\text { Opera } \\
\text { dor }\end{array}$ & $\begin{array}{l}\text { OP1 } \\
\%\end{array}$ & $\begin{array}{l}\mathrm{OP} 2 \\
\%\end{array}$ & $\begin{array}{l}\text { PRS1 } \\
\%\end{array}$ & $\begin{array}{l}\text { PRS2 } \\
\%\end{array}$ & $\begin{array}{l}\text { PRS3 } \\
\%\end{array}$ & TRIM & $\begin{array}{l}\text { peças/ } \\
\text { turno }\end{array}$ \\
\hline $\begin{array}{l}\text { OP1-PRS1/PRS2 } \\
\text { OP2-PRS3 } \\
\text { OP3-TRIM }\end{array}$ & 3 & 100 & 67 & 76 & 74 & 95 & 94 & 1095 \\
\hline $\begin{array}{l}\text { OP1-PRS1 } \\
\text { OP2-PRS2 } \\
\text { OP3-PRS3 } \\
\text { Fazer seu próprio } \\
\text { acabamento (TRIM) } \\
\text { Moldagem é } \\
\text { prioritária. } \\
\end{array}$ & 3 & 82 & 82 & 93 & 93 & 93 & 93 & $\begin{array}{l}630 \\
\text { [Trim } \\
\text { Wip } \\
\text { Build] }\end{array}$ \\
\hline $\begin{array}{l}\text { OP1-PRS1 } \\
\text { OP2-PRS2 } \\
\text { OP3-PRS3 } \\
\text { Fazer seu próprio } \\
\text { acabamento (TRIM) } \\
\text { TRIM é } \\
\text { prioritário. }\end{array}$ & 3 & 84 & 84 & 66 & 66 & 66 & 66 & 915 \\
\hline $\begin{array}{l}\text { OP1-PRS1/PRS2 } \\
\text { OP2-PRS3/TRIM } \\
\text { TRIM é } \\
\text { prioritário. }\end{array}$ & 2 & 94 & 94 & 76 & 29 & 29 & 72 & 840 \\
\hline $\begin{array}{l}\text { OP1-PRS1/PRS2 } \\
\text { OP2-PRS3/TRIM } \\
\text { TRIM é } \\
\text { prioritário. }\end{array}$ & 2 & 87 & 78 & 42 & 81 & 81 & 46 & $\begin{array}{l}540 \\
\text { [Trim } \\
\text { Wip } \\
\text { Build] }\end{array}$ \\
\hline
\end{tabular}

Obs.: TRIM= Prensa de Acabamento $\mathrm{WIP}=$ Estoque em Processo 


\section{Fabricação de Invólucro de Pneus e Assentos}

Um processo foi instalado para a produção invólucros revestidos para pneus e avêsso de tecidos para assentos para um novo modelo de automóvel. A instalação era projetada para uma produção anual de 64000 carros. A fabricação era por SRIM e o processo incluía a montagem da parte da frente com a de trás dos invólucros de pneus e a colagem de carpets. O processo foi simulado à medida que a produção começou, e, baseado nos resultados dessa análise, um segundo estudo foi realizado para recomendar um método de programação de operações (scheduling).

O processo apresenta uma complexidade maior que a experimentada para peças anteriores nessa instalação fabril. Cinco peças são fabricadas - dois avêssos de assentos, dois invólucros para pneus e um tecido direito de invólucro para pneu. Existem três seções de fabricação - pré-moldagem, moldagem, colagem e acabamento - cada uma das quais produz um mix diferente das cinco peças e estas devem ser montadas e empacotadas como conjuntos para os dois modelos.

A pré-moldagem é realizada pelo processo de colocação direta da fibra. Vidro picado e aglomerante são pulverizados por bocais distintos sobre uma tela porosa pela qual um vácuo é criado. A unidade de pré-moldagem possui quatro conjuntos de bocais de pulverização, capazes de pulverizar simultaneamente. Os fixadores porosos são unidos a módulos que giram em um carrossel do local da pulverização até o forno de cura do aglomerante, um estágio de resfriamento e um local de descarregamento.

Quatro invólucros de pneus ou avêssos de assentos podem se ajustar em um módulo da unidade de pré-fôrma. As pré-fôrmas dos invólucros de pneus consiste das seções da frente e da de trás, que estão separadas uma da outra antes da moldagem. Foi descoberto durante os primeiros processamentos que o fluxo de ar era inadequado para a operação apropriada, se mais do que dois avêssos de assentos estivessem afixados em um módulo. Assim, sem capital adicional para um soprador, o mix de produtos que pode ser produzido é tal que até dois avêssos de assentos ou até quatro invólucros de pneus podem ser fabricados em cada um dos quatro módulos. Com capital adicional, até quatro avêssos de assentos poderiam ser produzidos, e, se uma outra unidade de pré-fôrma existente na fábrica fosse também usada, várias outras combinações de produtos poderiam ser produzidas. Note que o número requerido de dispositivos devem ser adquiridos para produzir qualquer arranjo de pré-fôrmas.

Há um pulmão (buffer area) para os cinco tipos de pré-fôrmas e conjuntos de 50 a 100 de um dado tipo são transportados para a área de moldagem em carrinhos, onde eles são descarregados em pilhas próximas das prensas.

Existem duas prensas dedicadas a esse projeto. Os invólucros de pneus foram projetados para usar um tipo de resina, enquanto que os avêssos de assentos utilizam um outro tipo de resina. Portanto, o equipamento automatizado de injeção de resina é mais efetivamente usado se os invólucros de pneus e os avêssos de assentos forem feitos em prensas separadas. As prensas são suficientemente grandes para moldar dois 
conjuntos de invólucros de pneus e dois conjuntos de avêssos de assentos. Existe um conjunto de ferramentas.

A demanda por conjunto de peças para os dois modelos é comunicada semanalmente pelo cliente às segundas-feiras. Peças são enviadas por caminhão às sextas-feiras. A demanda de cada uma das quatro peças pode ser diferente e uma previsão para 13 semanas é fornecida. Essa previsão está sujeita a mudanças a cada semana.

\section{Simulação da Produção}

Utilizamos um software de simulação para modelar o processo, incluindo fluxo de peças, estoque em processo e carrinhos para cada seção. A operação do equipamento, o movimento das peças por meio dos carrinhos, a ação dos operadores e o volume de estoques em processo foram visualizados no modo animação no vídeo do computador.

Recursos do software (comandos "if/then", e comandos de espera) foram usados para projetar um procedimento de "puxar", para fornecer as taxas apropriadas de produção de cada peça em cada seção, para atender a demanda do cliente.

A lógica de decisão para enviar peças do estoque em processo de peças moldadas por carrinhos, em quantidades de 100 unidades, para a seção de colagem, é tal que apenas o tipo de peça programado para a colagem durante o turno deve ser enviado; carrinhos são requisitados no início de um turno ou quando o estoque na máquina de montagem é menor que 25, e nenhuma peça foram enviadas durante a última hora de um turno. A lógica deve considerar peças em trânsito para a máquina de montagem como parte do estoque ao decidir se um movimento de peça deve ser requisitado. Note que embora um homem pudesse tomar essa decisão pela sua observação, programar essa lógica em um computador não é trivial.

A simulação básica foi preparada para projetar condições. Isso fornece resultados em tabelas e figuras tais como máximo estoque em processo para cada pulmão, freqüência de bloqueio do equipamento, utilização do operador e do equipamento, como também giro dos produtos numa base horária.

Adquirimos conhecimento e sensibilidade a respeito de como seria o desempenho do sistema, quais os problemas que mais provavelmente terão impacto negativo, e como analisar qualidade e os custos dominantes. Encontramos acima de 60 estratégias operacionais possíveis, considerando configuração de unidades e programações. A unidade de pré-fôrma pode ser configurada de quatro maneiras primárias, considerando montagens de telas que determinam o mix de peças a qualquer momento. Também, pré-fôrmas podem ser deixadas para uma tela e vidro específicos, e, o pode ser fechado o aglutinador para cessar a produção de uma pré-fôrma, para a qual existe um alto estoque em processo sem mudança do dispositivo de fixação. "Programas balanceados" são necessários para compensar desbalanceamentos no mix 
de peças, quer entre invólucros de pneus e avêssos de assentos, que compõem conjuntos, quer para atender a demanda por diferentes modelos de veículos que não é geralmente a mesma. As prensas podem ser configuradas de duas maneiras primárias.

Seções de pré-fôrma e moldagem não utilizam totalmente seus equipamentos se os tempos de ciclo projetados são atingidos. Cada uma pode ser programada de duas maneiras básicas, em harmonia ou não com a outra.

A partir dessa análise, duas recomendações foram feitas:

Uma estratégia de operação preferencial, em que a eficiência do sistema é considerada como sendo a produção de blocos balanceados de conjuntos (de ambos: invólucros de pneus e avêssos de assentos) para um modelo de cada vez, na pré-fôrma, moldagem e colagem.

Uma metodologia de programação de operações usando ou um software de scheduling ou procedimentos de disciplina, deveria ser estabelecida.

A produção de blocos balanceados de conjuntos para cada modelo, num dado instante, em todas as seções de processo, deveria permitir uma programação de operações mais eficiente para acompanhar mudanças na demanda de conjuntos separados, requeridos pelo cliente, e deveria permitir a redução dos custos de mão-deobra. O procedimento original era programar as unidades de pré-fôrma e moldagem em termos de invólucros de pneus ou avêssos de assentos. Por exemplo, uma prensa era dedicada aos invólucros de pneus e uma aos avêssos de assentos. Conversão para prensas dedicadas aos conjuntos invólucros de pneus/avêssos de assentos de um modelo específico requer o uso de uma resina comum para todas as peças ou a instalação de um segundo sistema de injeção. Na unidade de pré-fôrma, mais telas são requeridas para produzir conjuntos para apenas um modelo por vez, permitindo, porém, a plena utilização do equipamento.

A necessidade de uma metodologia de programação de operações (scheduling) foi reconhecida, e a próxima seção trata da seleção de uma opção de programação de operações.

\section{Avaliação de Opções de Programação de Operações}

Quatro métodos de programação de operações foram considerados:

\section{Kanban;}

"despacho balanceado";

software feito sob medida;

otimização

Discussões foram mantidas com fornecedores de software e consultores de engenharia de produção. Nossas metas para uma programação de operações eram: risco mínimo de não atender as metas de entrega aos clientes;

baixos custos de mão-de-obra; e

baixos estoques em processo e de peças acabadas. 
A opção selecionada deveria ser caracterizada por simplicidade de operação e baixo investimento, consistente com o porte da empresa.

Os dois primeiros dentre os métodos de programação de operações acima foram simulados. Kanban, um método criado pela Toyota, caracteriza-se por "puxar" a demanda para disparar decisões sobre quando ou como processar de acordo com a chegada de containers vazios ou outros sinais de estações de trabalho subseqüentes. Definimos "despacho balanceado" como um método de "empurrar" envolvendo simples cálculo do computador e julgamento do homem para programar o equipamento numa base semanal, usando previsões mensais de demanda do cliente, atualizadas semanalmente pelo cliente.

O método do "despacho balanceado" envolve o entrelaçamento (no tempo) da programação balanceada de peças, programação de equipamentos e de dispositivos de fixação. para um mês, uma semana e cada turno. Isso é executado semanalmente, com o auxílio da planilha Lotus 1-2-3.

O resultado é o número de mudanças de operação requeridas para cada seção, em cada semana do mês, e os estoques em processo. A programação de cada mudança para cada seção é realizada pelo programador humano.

Um modelo simples de simulação é usado opcionalmente pelo programador para verificar sua seleção das programações dos equipamentos, turno a turno, para determinar se os equipamentos conseguirão operar conforme o planejado. O programa poderia mostrar o estoque em processo instantâneo e o estoque de peças acabadas durante a semana. Esse programa é baseado numa opção de software do ProModelPC, chamada PMI.

Uma característica central do método é um procedimento para programar a seção de pré-fôrma. Esta seção produz combinações de produtos que utilizam o equipamento de forma eficiente, mas que nunca balanceia a demanda do cliente. Assim, balanceamentos podem apenas ser perseguidos com base em prazos longos, digamos, uma ou duas semanas. O custo e a dificuldade de mudar os dispositivos de fixação fornecem um incentivo para programar sem balancear as combinações de produtos que efetivamente impõem maiores instabilidades ao sistema.

Desenvolvemos um método de predizer o número de revoluções do carrossel da pré-fôrma por intervalo de programação que força um balanceamento da produção de peças na pré-fôrma conforme a sua demanda necessária para satisfazer o cliente. Suponha-se que $\left\{X_{j}\right\}$ seja um vetor de demanda por unidade de tempo, para cada tipo de peça, e $\left\{\mathrm{A}_{\mathrm{ij}}\right\}$ é uma matriz cujas indicando a quantidade de cada peça, por revolução, para as diferentes configurações de dispositivos de fixação selecionadas, e $\left\{\mathrm{Y}_{\mathrm{i}}\right\}$ é um vetor do número de rotações por unidade de tempo para cada configuração.

$\mathrm{O}$ vetor de demanda, $\left\{\mathrm{X}_{\mathrm{j}}\right\}$, é conhecido, a matriz de pré-fôrma, $\left\{\mathrm{A}_{\mathrm{ij}}\right\}$, é selecionada com base no julgamento da engenharia, e o vetor de rotação, $\left\{Y_{i}\right\}$, é a incógnita.

Para que o balanceamento ocorra, a seguinte equação da álgebra linear deve ser satisfeita: $\left\{\mathrm{X}_{\mathrm{j}}\right\}=\left\{\mathrm{A}_{\mathrm{ij}}\right\}\left\{\mathrm{X}_{\mathrm{j}}\right\}$

onde representa o produto vetorial da matriz pelo vetor. 
A solução para o número de rotações para cada configuração é simplesmente:

$$
\left\{\mathrm{Y}_{\mathrm{i}}\right\}=\left\{\mathrm{A}_{\mathrm{ij}}^{-1}\right\} \quad\left\{\mathrm{X}_{\mathrm{j}}\right\}
$$

onde $\mathrm{A}^{-1}$ é a matriz inversa de $\mathrm{A}$. A operação de inverter uma matriz, requerida para resolver a equação (2), está disponível no Lotus 1-2-3 (data/matrix/invert), e isso foi incluído no programa de "despacho balanceado". Só será necessário realizar a inversão se uma nova configuração do dispositivo de fixação da pré-fôrma for desejada. Também, uma biblioteca de inversas pode ser desenvolvida para várias matrizes de configuração da pré-fôrma, e o programador pode acessar a biblioteca ao invés de executar a inversão da matriz.

Cuidado deve ser tomado para que o vetor solução represente uma resposta que faça sentido fisicamente (números não devem ser nem negativos nem imaginários) e que a matriz tenha inversa (matriz não-singular). Existem configurações de pré-fôrma que fazem sentido que levam a matrizes $3 \times 4$ que são singulares. Elas podem ser convertidas em matrizes não-singulares $4 \times 4$ ao adicionar uma configuração de dispositivo de fixação artificial que tem apenas um dispositivo de fixação na pré-fôrma e representa um vetor que gera o espaço nulo da matriz . A solução cobre o espaço nulo da matriz. $\mathrm{O}$ vetor solução, $\left\{\mathrm{Y}_{\mathrm{i}}\right\}$, buscará uma solução com zero revoluções para essa configuração, se a configuração e o vetor artificial forem escolhidos apropriadamente.

Nossa simulação mostrou que o Kanban não é adequado para lidar com a combinação de produtos em questão. Esse método é muito sensível em termos de sua resposta a alterações na demanda do cliente. Mão-de-obra será requisitada, por exemplo, se ocorrer um repentino aumento da demanda. Entretanto, para nossa aplicação onde decisões sobre combinação de produtos e mudanças de dispositivos de fixação são muito importantes, Kanban foi considerado inaplicável.

Sentimos que o esforço em encomendar um sistema de programação de operações sob medida seria tão grande quanto o envolvido em projetar o método do "despacho balanceado", o qual usa apenas um software planilha de cálculo. Assim nós recomendamos que sistemas de programação de operações comerciais não fossem considerados enquanto um sistema mais simples pudesse ser instalado e plenamente assimilado pelo staff da fábrica.

Os programas que realizam uma rigorosa otimização matemática são consideravelmente mais caros que os programas que se baseiam em relações heurísticas. Para entender por que a otimização matemática não é muito melhor que a programação heurística, para esta aplicação, note que a função custo envolve três elementos que podem ser tratados separadamente: entregas não efetivadas, mão-deobra e estoque. Cada um pode ser analisado por técnicas diferentes.

O componente mais importante de custo relaciona-se com o risco de não efetuar todas as entregas, que se relaciona com a confiabilidade das funções upstream. Estoques de peças acabadas podem ser usados como auxílio na minimização desse 


\begin{tabular}{|l|l|l|l|l|l|l|l|l|l|l|l|}
\hline \multicolumn{2}{|l}{ Recurso } & $\begin{array}{l}\text { Utili- } \\
\text { zação }\end{array}$ & \multicolumn{2}{l|}{ Recurso } & $\begin{array}{l}\text { Utili- } \\
\text { zação }\end{array}$ & \multicolumn{2}{l|}{ Recurso } & $\begin{array}{l}\text { Utili- } \\
\text { zação }\end{array}$ & \multicolumn{2}{l|}{ Recurso } & $\begin{array}{l}\text { Utili- } \\
\text { zação }\end{array}$ \\
\hline 1 & STORAGE & $20 \%$ & 11 & PAS2 & $34 \%$ & 21 & BA & $81 \%$ & 31 & UNLD1 & $25 \%$ \\
\hline 2 & TRIG2 & $0 \%$ & 12 & OPPR2 & $28 \%$ & 22 & PRP1 & $0 \%$ & 32 & WIPTCF & $0 \%$ \\
\hline 3 & PFLD & $100 \%$ & 13 & RES & $8 \%$ & 23 & MPRP & $4 \%$ & 33 & BFWT & $0 \%$ \\
\hline 4 & PREF & $27 \%$ & 14 & SB3 & $1 \%$ & 24 & OPDA & $34 \%$ & 34 & BF5 & $4 \%$ \\
\hline 5 & OPPF & $82 \%$ & 15 & RIM & $0 \%$ & 25 & TRIM & $17 \%$ & 35 & $\begin{array}{l}\text { BFETCB } \\
1\end{array}$ & $3 \%$ \\
\hline 6 & PREBA & $15 \%$ & 16 & NLD2 & $26 \%$ & 26 & LCRO & $10 \%$ & 36 & $\begin{array}{l}\text { BFETCB } \\
2\end{array}$ & $7 \%$ \\
\hline 7 & BFESB1 & $4 \%$ & 17 & PESB & $0 \%$ & 27 & PACK & $10 \%$ & 37 & LD & $39 \%$ \\
\hline 8 & BFS2 & $0 \%$ & 18 & BFW & $0 \%$ & 28 & BFTCF1 & $5 \%$ & 38 & PRS1 & $39 \%$ \\
\hline 9 & BFESB2 & $7 \%$ & 19 & BF4E & $3 \%$ & 29 & BFT2 & $0 \%$ & 39 & OPPR1 & $38 \%$ \\
\hline 10 & LD2 & $34 \%$ & 20 & LOAD & $81 \%$ & 30 & BFTCF2 & $15 \%$ & 40 & UNLOAD & $1 \%$ \\
\hline
\end{tabular}

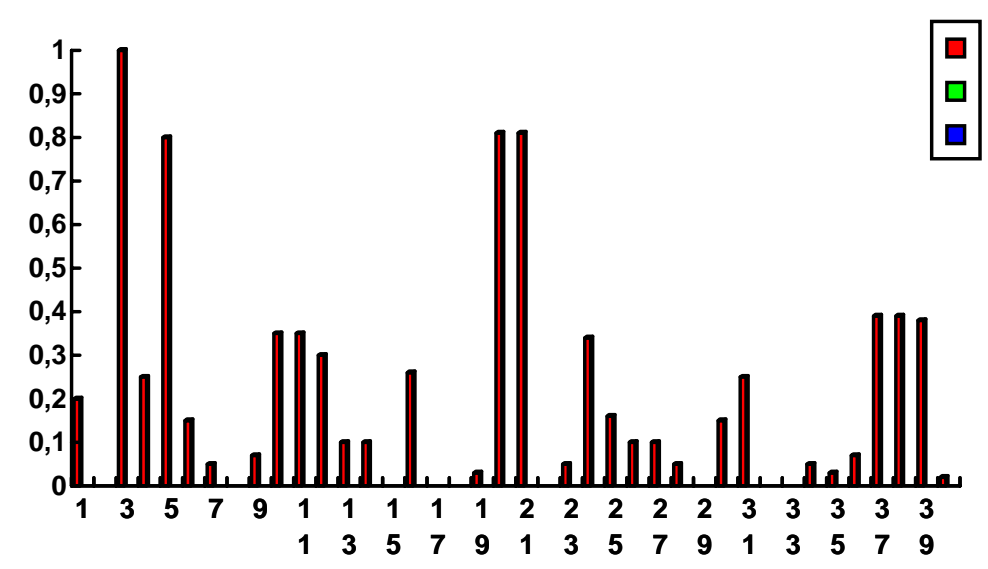

Figura 1: Sumário da Utilização dos Recursos

risco. Entretanto, é preciso ter cuidado para não usar recursos na otimização do próprio nível de estoques e deixar de lado o esforço para prevenir as causas da não confiabilidade.

Minimização da mão-de-obra poderia ser obtida por uma análise de Monte Carlo das várias configurações operacionais possíveis. O estoque em processo representa estoques de reserva específicos, de cada peça, em frente de cada unidade, que deve ser mantido acima de um dado nível para prevenir colapso da unidade. Níveis ótimos desses estoques poderiam ser encontrados, depois de encontrada a configuração que minimiza a mão-de-obra, mediante uma simulação tal como a PMI. Isso deveria estar próximo do ótimo global para mão-de-obra e estoque em processo já que as variações potenciais dos custos de mão-de-obra são maiores, e portanto mais importantes, que as dos estoques em processo. 


\section{Avaliação Global}

Avaliamos de forma positiva o emprego da simulação para entender, de modo global, como o sistema deveria operar. Nosso estudo abriu perspectivas que seriam difícilmente percebidas pelos engenheiros que tendem a focalizar seus esforços ou conhecimentos em áreas específicas.

Os custos dos pacotes de simulação estão decrescendo dramaticamente, enquanto que a facilidade em usá-los está aumentando também dramaticamente. Entretanto, o tempo de programação foi um ponto delicado. Vimos que os pacotes são projetados para a modelagem de sistemas segundo o esquema de "empurrar peças", enquanto que as operações devem "puxar" a produção para responder à demanda do cliente. Programar, segundo a lógica "puxar", foi responsável pela maior parte da complexidade da análise.

Deve haver centenas de maneiras de operar um sistema, e percebemos que deveríamos programar apenas uma ou duas opções, para ganhar uma visão geral do sistema. Fizemos então, para o grupo, uma apresentação das lições aprendidas, utilizando aparelhos visuais convencionais, sem usar a animação. Uma disponibilidade maior de recursos, na sala de conferência, para exibir a animação numa tela gigante, teria tornado a tecnologia da animação mais útil em termos de comunicação.

Cremos que o valor real da tecnologia só pode ser concretizada se houver um envolvimento direto no próprio ambiente do usuário. O apoio de especialistas é desejável, e problemas bem-definidos poderiam ser resolvidos por especialistas externos. Entretanto, simulação efetuada por especialistas externos sem envolvimento do pessoal do chão de fábrica, acarreta a perda da própria força da tecnologia da simulação.

\section{Conclusões}

Simuladores da manufatura estão, de forma dramática, se tornando mais baratos e de uso mais amigável em comparação com as gerações anteriores de simuladores da manufatura. A animação em tela pode aprimorar o nível de comunicação e entendimento em uma fábrica, ao unir pessoas da fábrica na identificação e tratamento de aspectos amplos e não óbvios do sistema. Isso pode se relacionar com a justificativa do novo investimento, seleção ou projeto dos sistemas de movimentação de materiais, procedimentos operacionais e programação de operações de fábricas já existentes. Existe, entretanto, uma curva de aprendizagem e a necessidade do grupo definir os recursos necessários.

Foi simulada detalhadamente uma instalação para produção de invólucros de pneus e avêssos de assentos para automóveis de luxo. Esta análise levou a recomendações com relação à filosofia de operação e à necessidade de uma metodologia formal de programação de operações. A filosofia operacional consistiu em produzir blocos de conjuntos de peças para um modelo de cada vez, em cada uma 
das seções do processo e programar as seções para operação em mútua harmonia. Isso exigiu a utilização de uma única resina, comum a todas as peças, e de dispositivos de fixação adicionais. Efetuou-se um estudo das opções de programação de operações, e recomendou-se um método de "despacho balanceado".

\section{Bibliografia Complementar:}

PAYNE, D.J.; THONDAVIDI, N.N.; FRANCIS, P.: "A Corporate Strategy for Implementing Process Simulation". Proceedings of the 1990 Winter Simulation Conference, Society of Computer Simulation, New Orleans (LA), December, 1990.

SCHONBERGER, R.J.: Japanese Manufacturing Systems. McMillan, New York, 1982.

SCRIVO, J.V.: "The Great Cover Up. A Third Generation SRIM Application". Proceedings of the Seventh Annual ASM/ESD Advanced Composites Conference, Detroit (Mich.), 30 September- 3 October, 1991.

\section{SIMULATION IN EVALUATION OF SCHEDULING POLICIES IN COMPOSITES MANUFACTURING.}

ABSTRACT-An assesment was made of the technology of manufacturing simulation of discrete part manufacturing for specific applications of a small polymer composites company. The objectives were:

ýAssess potential use for optmizing existing operations or for planning future projects and expansion;

ýSelect suitable software;

ýIdentify needed resources; and

ýRecommend an implementation plan.

It should be emphasized that the scope of the assessment was very specific to a small company's needs and that the search was limited to existing software packages that were easy to use and low in cost.

Simulation was applied to a new project, fabrication and carpeting of tire covers and seat backs for two automotive models. The Structural Reaction Injection Molding (SRIM) process was used fopr fabrication and carpet was applied in a bonding and assembly section. Capital and materials handling schemes has been determined previously, leaving operating modes and scheduling options as primary systems 
unknowns. Simulation of the process in operation provided a systems perspective leading to recommendations of operating strategies that were not obvious.

Key-words: simulation, scheduling, composites manufacturing. 